\title{
The Effect of Lossy Dielectric Objects On A UHF RFID Meander Line Antenna
}

\author{
Manimaran Kanesan, David V.Thiel, Steven G. O'Keefe \\ Centre for Wireless Monitoring an Applications, Griffith University \\ Nathan, Queensland, Australia \\ manimaran.kanesan@griffithuni.edu.au
}

\begin{abstract}
Meander line antennas placed on various objects suffer a shift in resonant frequency. Numerical modeling demonstrated that the frequency increases with wire diameter and object conductivity, and decreases with increasing permittivity. This contrasts with a linear dipole where an increase in wire diameter results in a decrease in resonant frequency. A $4 \%$ bandwidth is sufficient for conductivity $(\sigma)$ values up to $0.01 \mathrm{~S} / \mathrm{m}$ and small changes in permittivity. This has implications for RFID antennas designed for placement on a wide variety of materials.
\end{abstract}

\section{INTRODUCTION}

The first paper on modulated backscatter (the basic principle of passive RFID) was published in 1948 [1] and recent development of RFID technologies needs the antenna to be placed on variety of goods. Commonly the printed antennas are placed on adhesive, thin, plastic sheet [2]. The tag performance is governed by the wire radius and the material used to fabricate the antenna [3]. Problems arise when an antenna tuned for free space experiences a change in impedance when attached to objects with unknown electrical properties. The shift in resonance frequency $\left(f_{c}\right)$ results in a decrease in read range.

The RFID tag antennas with different conductor line widths printed on different substrates has been reported [3, 4]. These investigations did not report the effect of the electrical properties on the $f_{c}$. Meander line antennas are common in RFID applications [3-6], with the antenna performance optimized for different substrates by changing the thickness of the meander line antenna. Larger antenna bandwidth may solve this problem [7 - 9]. To reduce cost, the size of the tag is minimized, however the amount of conducting material (silver) is larger than in standard meander line antennas [10]. The introduction of a conductive ground plane further increases cost of a tag [8].

This paper reports the change in $f_{c}$ for meander line antennas with different wire radius located close to objects with different electrical properties. The effective $\sigma$ and permittivity $\left(\varepsilon_{r}\right)$ will vary significantly should the RFID tag be placed on such objects as glass and plastic containers containing liquids.

\section{MODELLING MeTHOD}

A linear dipole and a meander line antenna were modeled using the Numerical Electromagnetic Code (NEC) [11]. The NEC guidelines limit some aspects of the antenna design including wire radius and intersecting segment angle [12]. A centre-fed half wave linear dipole antenna at $850 \mathrm{MHz}$ was modeled in free space. The meander antenna structure [4] (see Fig. 1) was located $1 \mathrm{~mm}$ (centre to top surface) above a lossy object. The radius range valid for NEC models was $0.01 \mathrm{~mm}$ to $0.29 \mathrm{~mm}$. Both antennas were modeled using silver ink with conductivity $2 \times 10^{6} \mathrm{~S} / \mathrm{m}$ [3]. The first series resonance frequency was recorded in all cases reported here. In free space, $f_{c}=922 \mathrm{MHz}$.

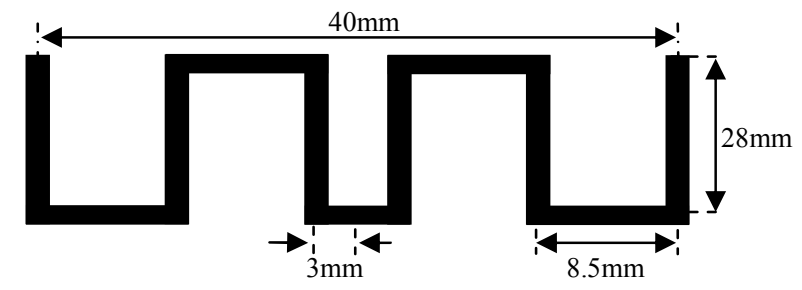

Figure 1. Meander line antenna model with dimensions. The antenna was fed at the centre of the $3 \mathrm{~mm}$ section.

\section{RESULTS}

The meander line antenna $f_{c}$ was determined for different wire radius and different object conductivities $\left(\sigma=10^{-7} \mathrm{~S} / \mathrm{m}\right.$ to $4 \times 10^{-2} \mathrm{~S} / \mathrm{m}$ ). The result for $\sigma=10^{-7} \mathrm{~S} / \mathrm{m}$ was identical to the result in air. The impedance bandwidth was 4\%. Fig. 2 shows a $1.4 \%$ decrease in $f_{c}$ for $\sigma<4 \times 10^{-2} \mathrm{~S} / \mathrm{m}$ for all radii values when $\varepsilon_{r}=1$. For larger $\sigma$ values, $f_{c}$ decreases significantly.

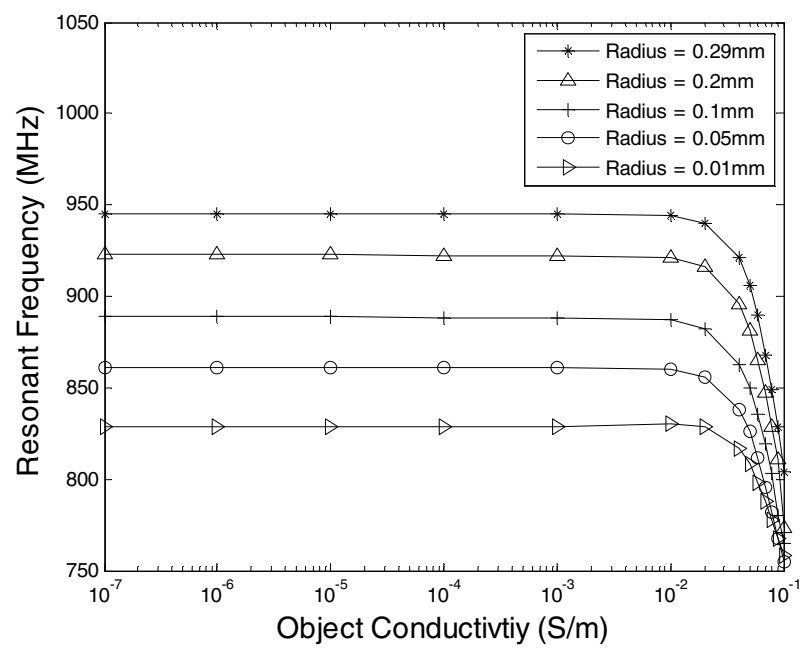

Figure 2. Meander line antenna $f_{c}$ with different radii located $1 \mathrm{~mm}$ above a lossy object with various $\sigma$ values. 
The variation in $f_{c}$ with radius is given in Fig. 3 for various $\sigma$ values. The half wave dipole in free space shows a $1.3 \%$ decrease in frequency across the radius range. The meander line antenna shows $f_{c}$ increasing with radius, but independent of $\sigma$ for $\sigma<10^{-2} \mathrm{~S} / \mathrm{m}$.

A meander line antenna with wire radius $0.2 \mathrm{~mm}$ in free space has a complex input impedance of $9-0.2 \mathrm{j}$ ohms. When the RFID chip has complex impedance, the resonance condition is changed and an alternative matching technique is required. One common option is the "T match" [3], [5- 6].

A change in $\varepsilon_{r}$ has a significant effect on the resonant frequency. The meander line antenna radius was fixed at $0.2 \mathrm{~mm}$. An increase in $\varepsilon_{r}$ greatly decreases $f_{c}$ (see Fig 4) but was independent of $\sigma$ (all lines are superimposed). The antenna resonance frequency shifted significantly when $\varepsilon_{r}$ was changed from 1 to 4 , but the rate of change decreased when $\varepsilon_{r}$ was changed from 4 to 8 .

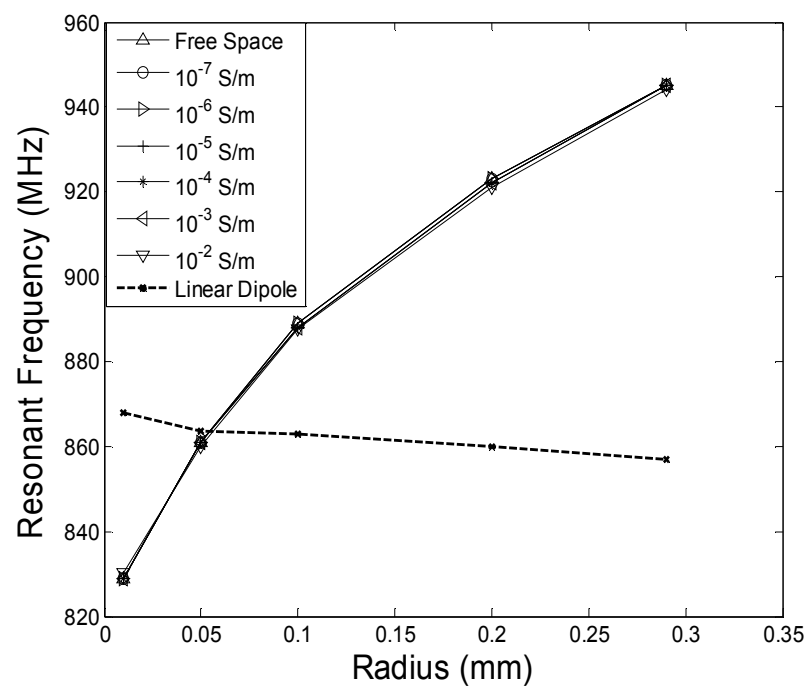

Figure 3. Variation in $f_{c}$ with radius for a linear half wave dipole in free space (broken line), the meander line dipole in free space (solid line superimposed), and on objects with various $\sigma$ values.

\section{CONCLUSION}

A $1.4 \%$ variation in $f_{c}$ when $\sigma<4 \times 10^{-2} \mathrm{~S} / \mathrm{m}$ is accommodated within the $4 \%$ impedance bandwidth of the meander line antenna. If the object is more conductive, then a much larger shift results and alternative, broadband antenna designs must be used. While an increase in the wire radius for the straight wire dipole shifts $f_{c}$ and increases the impedance bandwidth significantly, this is not the case for meander line antenna. Increasing $\varepsilon_{r}$ and $\sigma$ both resulted in a decrease in $f_{c}$. This effect was less than $4 \%$ over the relative permittivity range of $5-8$.

Common materials such as glass, wood and paper, cannot be completely accommodated by a single, simple meander line antenna, however this is possible if bandwidth is greater than $28.5 \%$. Several antennas suggested for RFID applications achieve a bandwidth of $10 \%[8,9]$. The antenna design by Okano [7] almost satisfies this requirement, the performance of this antenna has not been assessed under the same conditions.

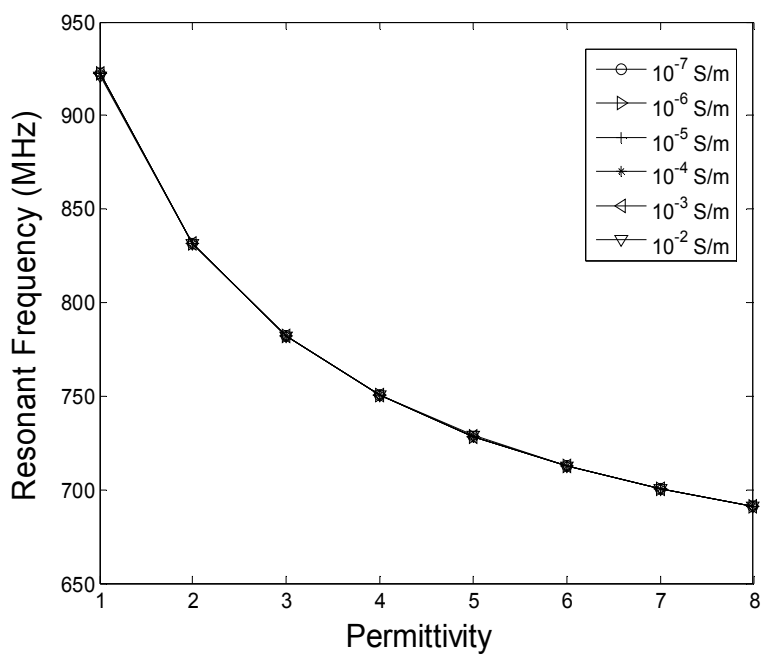

Figure 4. Variation in $f_{c}$ with $\varepsilon_{r}$ with fixed antenna radius of $0.2 \mathrm{~mm}$ and various $\sigma$ values (all lines are superimposed).

\section{REFERENCES}

[1] K. V. S. Rao, P. V. Nikitin, and S. F. Lam, "Antenna design for UHF RFID tags: A review and a practical applications," IEEE Trans. Antennas \& Propagation, vol. 53, pp. 3870-3876, Dec 2005.

[2] D. K. Finkenzeller, RFID Handbook: Radio-Frequency Identification Fundamentals and Applications, 2nd ed, New York: J. Wiley \& Sons, 2003.

[3] A. Syed, K. Demarest, and D. D. Deavours, "Effects of antenna material on the performance of UHF RFID tags", IEEE Int. Conference on RFID, pp. 57 - 62, March 2007.

[4] J. D. Griffin, G. D. Haldi, and B. Kippelen, "RF tag antenna performance on various materials using radio link budgets", IEEE Trans. Antennas \& Propagation Letters, vol. 5, pp. 247 - 250, 2006.

[5] C.Y. Cho, D.Y. Kim, H.S. Choo, and I. Park "Effect of the substrate, metal-line and surface material on the performance of RFID tag antenna", IEEE Int. Symp on Antennas and Propagation, pp. 1761 1764, June 2007.

[6] T. Deleruyelle, P. Pannier, M. Engels and E. Bergeret, "An RFID tag antenna tolerant to mounting on materials". IEEE Antennas and Prop. Magazine, vol. 52, no. 4, pp. 14-19, Aug 2010.

[7] Y. Okano, "A simple shape broadband planar antenna adaptable to RFID-tag”, IEEE Trans. Antennas \& Propagation, vol. 52, no. 6, pp. 1885-1888, June 2006.

[8] L. Xu., B. J. Hu, and J. Wang, "UHF RFID tag antenna with broadband characteristic", Electronic Letts, vol. 44, no. 2, pp. Jan 2008.

[9] D. D. Deavours, "Analysis and design of wideband passive UHF RFID tags using a circuit model”, IEEE Int. Conf. RFID, pp 283-290, 2009.

[10] A. Galehdar, D.V. Thiel and S.G. O'Keefe, "Tapered wire antenna design for maximum efficiency and minimum environmental impact", 8th Int Symposium ISAPE Kunming China, pp. 23-26, Feb 2008.

[11] Nittany Scientific Incorporation, "NEC-Win Plus User Manual", 2003.

[12] J. Peng, C. A. Balanis, and G. C. Barber, "NEC and ESP codes: Guidelines, limitations, and EMC applications", IEEE Trans. Antennas \& Propagation, vol. 35, no. 2, pp. 124 - 133, May 1993. 